\title{
Telemental health: videoconferencing in mental health services
}

\author{
Sridhar Vaitheswaran, Philip Crockett, Sam Wilson \& Harry Millar
}

\begin{abstract}
Sridhar Vaitheswaran is a
\end{abstract} consultant old age psychiatrist and Clinical Director for Old Age Psychiatry in NHS Grampian, UK, with interests in liaison old age psychiatry and service provision in remote and rural locations.

Philip Crockett is a consultant psychiatrist in psychotherapy and eating disorders and a group analyst. Based at Royal Cornhill Hospital in Aberdeen, UK, he is also the clinical lead for the North of Scotland Eating Disorders Managed Clinical Network. Research interests include the use of technologies in eating disorders and psychotherapy, group-based interventions and the acute ward environment. Sam

Wilson is a consultant genera adult psychiatrist. He is based in Aberdeen and Orkney, UK. His interests are undergraduate and postgraduate medical education and service provision to remote and rural locations. Harry Millar is forme consultant psychiatrist in general psychiatry and eating disorders for NHS Grampian. His interests have included postgraduate training,

service development, clinical uses of videoconferencing, electronic records and research into the epidemiology of eating disorders.

He undertook a review of telemental health for the Scottish Centre for

Telehealth in 2009

Correspondence Dr Philip

Crockett, Consultant Psychiatrist,

Royal Cornhill Hospital,

Aberdeen AB25 2ZH, UK. Email:

philipcrockett@nhs.net

\begin{abstract}
SUMMARY
Video technology was first used in psychiatric services in the 1950s but came into general use in the 1990s, particularly in North America and Australia. Video has utility across all ages and in a wide range of clinical situations. These include case conferencing for patients with complex problems (e.g. when planning discharge from specialist in-patient units), psychological assessment and treatment, Mental Health Act assessments, suicide risk assessment and work in forensic settings. Potential for benefit may be most obvious in remote locations, but video use is also relevant in urban settings. Lack of training and experience, inadequate access to equipment and insufficient technical support have all limited the take-up of this technology in the UK. This article briefly reviews the literature and outlines technical and cost considerations when using video technology. Three services in Scotland are described to illustrate ways in which videoconferencing can enhance services.
\end{abstract}

\section{DECLARATION OF INTEREST}

None.

The Royal Australian and New Zealand College of Psychiatrists defined telepsychiatry as 'the use of communication technology to provide psychiatric services from a distance' (Royal Australian and New Zealand College of Psychiatrists 1999). The technologies can include landline phones, mobile phones (using voice and/or texting), e-mail, social networking websites, illness-specific computer programmes (which are increasingly now web-based), 'smart technology' in the patient's home (such as door sensors or GPSbased systems to monitor a person's movements) and videoconferencing. Some of these can be used together and combined with face-to-face interactions with patients. This article focuses on the use of videoconferencing to provide clinical services. The term 'telemental health' is preferred because it encompasses interactions involving any mental health professional, not just psychiatrists.

Many clinicians have experience of using videoconferencing occasionally, usually for administrative and educational purposes, but a review undertaken by one of the authors for the Scottish Centre for Telehealth (Millar 2009) found few services using videoconferencing routinely for clinical purposes in Scotland. Unfortunately, the occasional users often reported poor experience, with difficulties booking and setting up equipment; poor room acoustics, lighting and furniture layout; and/or technical hitches with no or limited back-up. As a result, most services do not use videoconferencing regularly for clinical purposes. However, where these problems are addressed, and this article will provide some help to do this, regular users have a more positive view of the value of videoconferencing.

Videoconferencing for clinical purposes has obvious potential for small, far-flung communities, such as those in the Highlands and islands of Scotland. Videoconferencing will also become increasingly popular in urban areas, because economic analysis needs to factor in: increasing costs of travel around congested cities; decreasing costs of technology; and increased travel times for clinicians. Carbon costs will also need to be taken into account. In addition, usage is likely to grow with improvements in reliability, quality and access.

Clinical take-up of videoconferencing has been limited. In a survey of all psychiatrists in Scotland (Millar 2009), of the small number (26) commenting on their use of videoconferencing, $23 \%$ rated their experience as poor or very poor, $35 \%$ as 'usable' and $42 \%$ as good or excellent. Problems reported included inadequate access in psychiatric clinical areas, technical problems in setting up and maintaining a connection, lack of bridging facilities for multiple sites and a lack of technical support and training.

This article briefly reviews the literature, discusses the main technical considerations, outlines an approach to cost-benefit analysis and gives practical advice in the context of descriptions of services regularly using videoconferencing.

\section{Literature review}

The first reports of the use of telemedicine come from the USA. In 1950s' Nebraska, twoway closed circuit television was used, mainly in psychiatry (American Academy of Child \& 
Adolescent Psychiatry 2008). In 1973, a report from Massachusetts General Hospital coined the term 'telepsychiatry' to describe the consultation services provided from the hospital to another site in Boston. However, presumably because of technological limitations and cost, significant numbers of studies did not appear until the 1990s.

There has been a number of detailed reviews of the literature, including a book on telepsychiatry (Monnier 2003; Wootton 2003, 2006; Pesamaa 2004; Leach 2006; Norman 2006; Hailey 2007; American Academy of Child \& Adolescent Psychiatry 2008; Millar 2009). One systematic review of 106 studies across the whole of medicine concluded that 'telemedicine is most effective for verbal interactions, e.g. videoconferencing for diagnosis and treatment in specialties like neurology and psychiatry' (Hersh 2006, p. 3).

The literature includes services for children, adolescents and the elderly, as well as for general adults. Emergency assessments, checks for suicide risk and legal detention procedures can all be done successfully, as can more general assessments. A Scandinavian study has also shown videoconferencing for care planning to be satisfactory (Mielonen 2000) and a Scottish child psychiatry report described similar results (Mitchell 2009).

Videoconferencing has been used successfully for psychological assessments and treatments and there are two long-established service implementations in Scotland in the Grampian Eating Disorders Service (see below) and the Arran Counselling Service. Studies have shown that, for most patients, there is a satisfactory therapeutic alliance and some patients report a preference for treatment via videolink (Capner 2000; Simpson 2001; Day 2002). Remote supervision of therapists can also successfully be arranged using videoconferencing (Gammon 1998).

Some highly specialised services have made use of videoconferencing. These include services for the deaf, the support of a remote clinic by the US military (Grady 2002) and prison services (Zaylor 2001). In secure settings, the use of video can reduce the need for expensive staff escorts for patients to access clinicians outside or timeconsuming security procedures for specialists entering a prison or a secure hospital.

Although many studies are fairly small scale and lack controls, the overwhelming evidence is that the use of videoconferencing is a feasible option for patients in remote settings who could not otherwise access specialist mental health services. UK and US studies report good patient satisfaction (Cruz 2005; Norman 2006), with patients reporting a sense of security and of greater control of the situation, feeling less threatened and less inhibited (Simpson 2005). Clinicians report slightly lower levels of satisfaction than patients in some studies, which may reflect clinician anxiety about picking up non-verbal communication such as eye contact, facial expressions and subtle changes in voice quality, which may be important in determining the patient's emotional state. In a US study of psychotherapy using distance technology, the patient's activity level, initiative, trust, spontaneity and disinhibition were unaffected (Day 2002).

In Canada, the Institute of Health Economics undertook a detailed review of the harder evidence of benefits from telemental health including telephone- and internet-based studies, as well as video (Hailey 2007). Most of the studies had a comparator and the overall finding was that $80 \%$ showed successful or potentially successful outcomes. Successful videoconferences included case management for depression, panic disorder and bulimia nervosa, as well as cognitive function assessments in the elderly.

\section{Technical considerations}

The technology used in telemental health service provision is rapidly evolving. Progress has made technology more accessible, but it can also be challenging to keep the systems updated to run a consistent service. Rather than concentrating on understanding all of the terminology in detail, perhaps an important consideration for most practitioners will be a healthy relationship with their communications team. Ideally, the team will contain a contact for supporting equipment use, translating technical language, helping with equipment failure and maintaining the equipment. An organisation developing a telemental health service will need to be sure that the equipment is adequate, which will most likely be determined by a local communications team.

\section{Local preparation}

The setting of the videoconference room is important. High levels of background noise, poor or excessive lighting or kit positioning can all be major stumbling blocks on the day, but can often be swiftly solved with the right advice. A videoconference session needs a little extra time allocated at the beginning to make sure that the link is established and that there is a list of handy phone numbers if the call does not connect, including for the local communications base contact, who can sometimes remotely solve problems as they occur. It is important to know the 'call in' number, or internet protocol (IP) address, of the local and remote screens. Occasionally, 
adverse weather conditions can impede remote links and sessions may have to be rescheduled.

\section{Maintaining peripheral equipment}

The maintenance and nature of equipment at the other end of the link(s) can be as important as local preparation. Therefore, there is a need for maintaining not only the base equipment, but also all of the peripheral units. This can be a challenge as the units may be supplied by different healthcare organisations. In practice, we have found that problems arise when one kit is considerably older than the other or when the manufacturers differ.

\section{Technical confidence}

Many technical hitches can be fixed by someone on site with a little knowledge (e.g. a cable not plugged in or a part of the kit not switched on). Basic confidence in using equipment for telemental health is easily gained with a little practice and observation; it is less important to understand the technology fully, as long as good advice is available readily. On the other hand, if the telemental health service is being developed in a region with less communications support, more technical knowledge for the clinician may be more important. Table 1 gives a brief account of important technical and practical considerations that may be useful for clinicians setting up a videolink service.

\section{Security issues}

Internet technology often used at home may be more familiar to the health practitioner: whether

TABLE 1 Advice for videolinking in mental health

\begin{tabular}{|lll|}
\hline & Do & Do not \\
\hline $\begin{array}{l}\text { Technical } \\
\text { considerations }\end{array}$ & $\begin{array}{l}\text { Use the local communications department } \\
\text { to ensure that the equipment is } \\
\text { compatible with your network }\end{array}$ & $\begin{array}{l}\text { Buy equipment without } \\
\text { benchmarking with other areas } \\
\text { or other guidance }\end{array}$ \\
\hline $\begin{array}{l}\text { Preparation of } \\
\text { the room }\end{array}$ & $\begin{array}{l}\text { Check audibility and lighting at the outset. } \\
\text { Problems may rapidly appear that are } \\
\text { easily resolved }\end{array}$ & $\begin{array}{l}\text { Start a call without first } \\
\text { checking the environment }\end{array}$ \\
\hline $\begin{array}{l}\text { Getting ready to } \\
\text { use facilities in } \\
\text { a service }\end{array}$ & $\begin{array}{l}\text { Test the equipment and practise before } \\
\text { your first live session }\end{array}$ & $\begin{array}{l}\text { Start a session without any } \\
\text { previous experience of the } \\
\text { equipment }\end{array}$ \\
\hline $\begin{array}{l}\text { Preparation for } \\
\text { a call }\end{array}$ & $\begin{array}{l}\text { Have contact phone numbers for the unit } \\
\text { with which you are linking and for your } \\
\text { communications department. Have a plan } \\
\text { for what to do if the link goes down }\end{array}$ & $\begin{array}{l}\text { Assume that everything will } \\
\text { go without a hitch or that if } \\
\text { you can see and hear the other } \\
\text { participants they can see and } \\
\text { hear you (or vice versa) }\end{array}$ \\
\hline $\begin{array}{l}\text { Managing a call } \\
\text { videolink } \\
\text { service }\end{array}$ & $\begin{array}{l}\text { Practise using the camera and audio } \\
\text { controller and be prepared to use it. } \\
\text { Check that the other participants are } \\
\text { happy with the videolink contact }\end{array}$ & $\begin{array}{l}\text { Attempt videolink without basic } \\
\text { knowledge of the control options }\end{array}$ \\
$\begin{array}{l}\text { Cultivate contacts for the regular } \\
\text { videolink sites and, if possible, book well } \\
\text { in advance if there is high demand }\end{array}$ & $\begin{array}{l}\text { Assume that other sites will } \\
\text { always have space for a } \\
\text { videolink session }\end{array}$ \\
\hline
\end{tabular}

it be Skype or other use of webcams. All of these might have their uses in health settings, but again advice would be essential. For instance, there are major data protection issues over Skype and quality depends on the equipment available. As security systems improve, cheaper technology may become more acceptable.

\section{Costs}

A review by Hyler \& Gangure (2003) of Englishlanguage studies found only 12 studies of variable quality with samples of more than 10 people in programmes focused specifically on the cost of telepsychiatry. They emphasise the importance of comprehensively reviewing all costs, including direct costs, indirect costs and hidden costs. Other studies structure the costs into fixed costs and variable costs (Persaud 2005) and note the importance of identifying costs to the provider, costs to the patients and an overarching societal cost in taking account of both (Hailey 1999; Persaud 2005).

Hyler \& Gangure (2003) found seven studies that reported telepsychiatry to be worth the cost, one study that suggested telepsychiatry was not financially viable and three studies that reported no significant differences in costs between telepsychiatry and traditional face-to-face psychiatry. In a US study comparing the costs of a telepsychiatry service with those of a visiting psychiatrist service, Ruskin et al (2004) found that once the psychiatrist had to travel more than 22 miles, the time and travel cost to the provider made staying at the base hospital and providing telepsychiatry cheaper. One study in an urban setting in Hong Kong (Tang 2001) found that the cost for each video consultation in a psychogeriatric service to a care home only $3 \mathrm{~km}$ from the base hospital was reduced by $13.2 \%$ compared with face-to-face consultations. The high volume of use and the extensive parallel use by other services (the 149 psychiatric consultations in the study comprised $8.3 \%$ of all video consultations) kept the unit cost for each psychiatric video consultation low.

Table 2 summarises the main variables that should be considered when comparing the use of videoconferencing with a face-to-face service.

\section{Videoconferencing in practice}

\section{Grampian Eating Disorders Service}

Grampian Eating Disorder Service is an out-patient service based in Aberdeen, Scotland and serves a population of 593000 , including the Northern Isles. It has been using videoconference facilities since 2004, providing contact for patients with 
eating disorders, families and care professionals, and for participating in various regional meetings. The unit has used this link to work with patients in diverse distant locations in Grampian on the mainland, the Orkney Islands and the Shetland Islands, usually via equipment at doctors' surgeries and local hospitals.

There are two sets of videoconferencing equipment in the out-patient service base in Aberdeen - one set is located in a smaller room that is used mainly for therapy sessions, and the other is in a larger room that is used for meetings and psychiatric reviews. The service is supported by a well-developed communication support service and secretaries keeping a bookings diary. This is essential because demand for access to the facilities from other mental health services in Grampian is gradually increasing.

A regional eating disorders in-patient unit has also been established with its own dedicated videoconferencing kit.

Grampian Eating Disorders Service gets around 200 out-patient referrals a year and around 20 contacts of varying nature a month are done using the videoconferencing equipment. It has proved vital for service provision in terms of the region covered and the patients' needs being met appropriately. Therapists, psychologists, dietitians and psychiatrists all make use of the equipment.

Simpson and colleagues $(2005,2006)$ studied the use of telemedicine in the Grampian Eating Disorders Service setting in a small case series and demonstrated a good degree of user satisfaction as well as a therapeutic change in usual measures for bulimia nervosa. Our experience with patients in therapy is that good preparation of the distant room, as well as the patient, is essential. For example, equipping the room with notepaper and pens and sending therapy-related material in advance to the patient can help to facilitate the session.

Use of telemedicine in Grampian Eating Disorders Service has been especially meaningful when working with patients for whom travel presents significant physiological challenges and who often appreciate less disruption to their familiar routines. The department records the number of sessions delivered in this format; the intention is to review service user satisfaction to refresh our knowledge of its impact on the delivery of eating disorder services in NHS Grampian.

\section{Case vignette: Treating anorexia nervosa via videolink $^{a}$}

Miss A, aged 26, was referred by her general practitioner (GP) at a body mass index of 14.5 with falling weight, restriction of food intake and over-exercising. She had iron-deficiency anaemia.
TABLE 2 Cost variables in telemental health

\begin{tabular}{|ll|}
\hline Face-to-face clinic & Effect \\
\hline Distance travelled by patient & Increased distance increases cost to patient \\
\hline Distance travelled by clinician & Increased distance increases cost to provider \\
\hline Type of travel & $\begin{array}{l}\text { Air: expensive but may save time costs on } \\
\text { longer journeys } \\
\end{array}$ \\
& Ferry: only option for many journeys \\
& $\begin{array}{l}\text { Car: time efficient on mainland } \\
\text { Public transport: time inefficient for most } \\
\text { mainland journeys }\end{array}$ \\
\hline Clinician travel time & Increased time increases cost to provider (plus \\
& subsistence costs possible) \\
\hline Video clinic & Effect \\
\hline Sharing equipment with other services & Reduces clinic costs \\
\hline Equipment already installed & Reduces clinic costs \\
\hline Research funding & Can reduce costs \\
\hline Volume of clinical activity & High volume reduces unit costs \\
\hline Costs of line rental and calls & High volume reduces unit costs \\
\hline Cost of maintenance and technical support & High volume reduces unit costs \\
\hline
\end{tabular}

She lived in a small, distant, rural community and at her initial assessment in the Aberdeen clinic she was diagnosed with anorexia nervosa. Miss A was subsequently seen by videolink once or twice weekly by the dietitian and a team psychiatrist. The dietitian was able to set weight targets that her local general practice monitored. The psychiatrist initially focused on Miss A's motivation and liaised with the GP to monitor physical parameters, including electrocardiograms and blood tests. An individual therapist was allocated and a regular review with the team psychiatrist and dietitian continued. Occasional visits to Aberdeen, including one for a bone-density scan, were added to help boost engagement with the service, and family members were involved over the videolink. The patient made steady progress over 18 months in terms of her physical and psychological health and improved her social functioning, managing to return to work.

\section{Orkney General Adult Psychiatry Service}

The Orkney Islands are an archipelago off the far north-east of mainland Scotland. Most of the population lives on the main island and there are road, ferry and air links to the other islands. Winter weather can prevent travel, even between the islands linked by bridges. A community mental health team of around eight community psychiatric nurses, one clinical psychologist, one occupational therapist, two social workers and three support workers provide psychiatric services to a population of approximately 16000 adults of working age and older. Medical psychiatric services are provided 2 days a week by a psychiatrist onisland and the rest of the time at a distance from Aberdeen, where in-patient facilities are located. a. The case vignettes in this article are fictitious. 
The 16 GP surgeries on the islands, the hospital in Orkney and many local authority and voluntary sector units have videolink facilities with a variety of equipment. Administrative staff from the community mental health team arrange appointments. Telemedicine has been established for many years in Orkney, but it has only been used regularly in psychiatry since October 2009.

A major benefit of videoconferencing has been in clinical and organisational meetings. This has been highly satisfactory for the participants, has reduced travel time and has allowed more capacity for face-to-face appointments with patients.

A videolink is used to assess new patients and to review existing out-patients and recently discharged patients from the in-patient unit in Aberdeen. Patients are selected for videolink appointments because of travel difficulties and so far all have accepted the appointments, which are arranged 4 weeks in advance. A member of staff switches the unit on at the remote site but the patient is unaccompanied during the interview.

In 2010, there were 41 out-patient appointments offered for videolink consultation. Twelve were for new patients and 29 for reviews; 23 of these appointments were completed. Four failed during the consultation owing to connection problems but not until after a sufficient clinical encounter to allow assessment and formulation. Seven patients cancelled or did not attend and 7 appointments did not occur because of administrative difficulties.

As yet, the full potential for service improvement has not been realised. There is a need to address administrative issues such as arranging videolink appointments, consultant psychiatrist's time not being flexible enough to accommodate suitable appointments and lack of administrative staff dedicated to facilitating videolinks. Compared with face-to-face appointments, arranging a videolink appointment still involves more lines of communication and requires more coordination.

However, the majority of patients who had videolink appointments in Orkney in 2010 said that they were satisfied with the system. Even the one patient who expressed dissatisfaction preferred to be seen this way for subsequent appointments, rather than having the inconvenience of travelling.

\section{Case vignette: Assessing schizophrenia via videolink}

Mr B had a long history of schizophrenia and serious suicide attempts. He generally recovered quickly but continued to lack insight even when well. Endeavours had been made to manage him on a voluntary basis in the community. He often stopped taking medication and relapsed, requiring transfer to the base hospital in Aberdeen.

After a second relapse, a decision was made to apply for a compulsory treatment order. In Scotland, this type of application requires a second report from patients' GPs, who will often have difficulty supplying these reports because they may have to cancel surgeries and travel long distances. Sometimes another psychiatrist provides the second report instead, which can be open to legal challenge. In this case, the problem was made more difficult because the GP was in Orkney and the patient was in Aberdeen.

The patient was interviewed by videoconference at a suitable time, with the patient in Aberdeen and the GP in Orkney. The GP provided his report on the basis of this interview and the mental health tribunal accepted his evidence when they met in Aberdeen. The patient was discharged to the community on leave. An application was made to change the order from hospital-based to community-based. The tribunal sat in Aberdeen with the psychiatrist present, while the patient and mental health officer attended by videoconference in Orkney. The application was successful.

\section{Shetland Dementia Service}

Shetland is an archipelago of more than 100 islands situated in the North Sea. The 2007 midyear population stood at 21950 , of whom 3640 were aged 65 and over. As with other rural regions in Britain, it is an ageing population. It is projected that by 2030 , there will be 2175 more individuals aged 65 and over, an increase of $16.6-26.5 \%$ of the total population. There will also be a $20.9 \%$ decline in the working-age population during the same period, which will have implications in planning for services to cater for the needs of the growing elderly population. Until January 2010 , there was no specialist dementia service in Shetland and there was no clear pathway for diagnosis and management for persons with dementia. General practitioners and physicians managed problems as they arose and occasionally people with dementia were referred for specialist assessment in Aberdeen, which required travel for them and their relatives with overnight admission in hospital, plus accommodation for relatives.

The Dementia Service for Shetland was set up in January 2010 and comprises one wholetime equivalent, band 8 a dementia development services manager, who is an experienced community psychiatric nurse based in Lerwick (the capital of Shetland), and a committed session from a consultant old age psychiatrist, based in Aberdeen, 210 miles south. The input from the consultant old age psychiatrist mainly consists of regular weekly videolink session lasting 2 hours to include clinical supervision of the dementia services development manager and assessment of patients with dementia. Another 2 hours of the consultant's time are devoted to administrative work, education for staff in Shetland using videoconferencing and service development. 
Referrals from GPs, hospital doctors and the consultant general adult psychiatrist based on the island are discussed at the weekly videolink meetings with the manager by the consultant old age psychiatrist. If the referrals are accepted, the manager makes an initial assessment and discusses the history and findings again with the consultant via videolink at the next available session. If there are uncertainties or if further assessment by the consultant is required, the person with suspected dementia and a relative are asked to attend telemental health assessment at the community mental health service base in Lerwick, which has videolink facilities. The dementia services development manager is present during these sessions to facilitate and coordinate the assessment. Gilbert Bain Hospital in Lerwick has computed tomography (CT) scanning facilities that can be used if appropriate. The manager often discusses diagnoses of dementia with the patients and their carers during a follow-up visit and appropriate information is provided. If necessary, the videolink facilities are used by the consultant to provide information and to discuss the diagnoses with the persons with dementia and their carers. The GPs are requested to provide prescriptions for acetylcholinesterase inhibitors and other psychotropic drugs in the management of dementia. Follow-up assessments are carried out by the manager and are discussed with the consultant via regular videolinks.

The Shetland Dementia Service received 64 referrals between February 2010 and January 2011. The overall experience for the persons with dementia and their carers appeared to be satisfactory. The clinicians involved in the process have also found it to be useful and satisfactory. There were occasions when it had been difficult to book a facility in Aberdeen for a session but this has been overcome by a computer-based programme in the consultant's office that allows the videolink to be achieved via webcam. The communications team based in NHS Grampian has been extremely helpful in times of technical difficulties, which have been rare.

\section{Case vignette: Diagnosing dementia via videolink}

Mr C, aged 69, was referred by the consultant general adult psychiatrist in Shetland with a few years' history of depressive symptoms that were resistant to treatment and also a recent wordfinding difficulty. He was initially assessed in person by the dementia services development manager and subsequently by the consultant via videolink. $\mathrm{MrC}$ presented with stereotypical movements and also showed significant impairment in frontal lobar function tests that were performed via the videolink with the dementia services development manager facilitating them. A provisional diagnosis of frontal lobe dementia was made and he was referred for a CT head scan in Lerwick, which confirmed bilateral frontal lobe atrophy. The diagnosis was discussed with $\mathrm{Mr} \mathrm{C}$ and his family via videolink and they are being supported on the island by the dementia services development manager.

\section{Conclusions}

Use of telemedicine in mental health settings can help to solve many of the problems in effective service provision in remote and rural regions, notably by improving equality of access. It also provides patients and relatives with varied models of care that traditionally have been difficult, if not impossible, to deliver. It reduces professional isolation of health and social care staff working as lone practitioners. In addition, it reduces the cost of provision of services in areas of geographical isolation, where the tradition of only providing services via visiting consultants and other clinicians or by patients travelling to the mainland has proven to be expensive. Telemedicine saves time, not only for the clinicians involved in the provision of care, but also for the healthcare users. Also important is the contribution that the reduction in travel makes to cutting the overall carbon footprint. To deliver satisfactory results, services need to adapt to local needs and require adequate support systems. However, with limited training it is possible for a motivated team of clinical, administrative and technical staff to provide an excellent and much appreciated service.

\section{References}

American Academy of Child \& Adolescent Psychiatry (2008) Practice parameter for telepsychiatry with children and adolescents. Journal of the American Academy of Child and Adolescent Psychiatry 47: 1468-83.

Capner M (2000) Videoconferencing in the provision of psychological services at a distance. Journal of Telemedicine and Telecare 6: 311-9.

Cruz M, Krupinski EA, Lopez AM, et al (2005) A review of the first five years of the University of Arizona telepsychiatry programme. Journal of Telemedicine and Telecare 11: 234-9.

Day SX, Schneider PL (2002) Psychotherapy using distance technology: a comparison of face-to-face, video and audio treatment. Journal of Counselling Psychology 49: 499-503.

Gammon D, Sorlie T, Bergvik S, et al (1998) Psychotherapy supervision conducted by videoconferencing: a qualitative study of users' experiences. Journal of Telemedicine and Telecare 4 (suppl 1): 33-5.

Grady BJ (2002) A comparative cost analysis of an integrated military telemental health-care service. Telemedicine Journal and e-Health 8: 293-300.

Hailey D, Jacobs P, Simpson J, et al (1999) An assessment framework for telemedicine applications. Journal of Telemedicine and Telecare 5 : 162-70.

Hailey D, Roine R, Ohinmaa A (2007) Evidence of Benefits from Telemental Health: A Systematic Review. Institute of Health Economics (http://www. ihe.ca/documents/IHE_Report_Evidence_of_Benefits_Telemental_ Health_Oct_2007.pdf).
MCO answers

$1 \mathrm{~b} \quad 2 \mathrm{~d} \quad 3 \mathrm{c} \quad 4$ e $\quad 5$ a 
Hersh WR, Hickam DH, Severance SM, et al (2006) Diagnosis, access and outcomes: update of systematic review of telemedicine services. Journal of Telemedicine and Telecare 12 (suppl 2): 3-31.

Hyler SE, Gangure DP (2003) A review of the costs of telepsychiatry. Psychiatric Services 54: 976-80.

Leach LS, Christensen H (2006) A systematic review of telephone-based interventions for mental disorders. Journal of Telemedicine and Telecare 12: $122-9$

Mielonen ML, Ohinmaa A, Moring J, et al (2000) Psychiatric inpatient care planning via telemedicine. Journal of Telemedicine and Telecare 6: $152-7$.

Millar HR (2009) Telemental Health in Scotland. Scottish Centre for Telehealth (http://www.sctt.scot.nhs.uk/pdf/mentalhealth.pdf).

Mitchell SA, MacLaren AT, Morton M, et al (2009) Professional opinions of the use of telemedicine in child and adolescent psychiatry. Scottish Medical Journal 54: 13-16.

Monnier J, Knapp RG, Frueh BC (2003) Recent advances in telepsychiatry: An updated review. Psychiatry Services 54: 1604-9.

Norman S (2006) The use of telemedicine in psychiatry. Journal of Psychiatric and Mental Health Nursing 13: 771-7.

Persaud DD, Jreige S, Skedgel C, et al (2005) An incremental cost analysis of telehealth in Nova Scotia from a societal perspective. Journal of Telemedicine and Telecare 11: 77-8.

Pesamaa L, Ebeling H, Kuusimaki JL, et al (2004) Videoconferencing in child and adolescent telepsychiatry: a systematic review of the literature. Journal of Telemedicine and Telecare 10: 187-92.
Royal Australian and New Zealand College of Psychiatrists (1999) Position Statement \#44: Telepsychiatry. Royal Australian and New Zealand College of Psychiatrists (http://www.ranzcp.org/Files/ranzcpattachments/Resources/College_Statements/Position_Statements/ ps44-pdf.aspx).

Ruskin PE, Silver-Aylaian M, Kling MA, et al (2004) Treatment outcomes in depression: comparison of remote treatment through telepsychiatry to in-person treatment. American Journal of Psychiatry 161: 1471-6.

Simpson S (2001) The provision of a telepsychology service to Shetland: client and therapist satisfaction and the ability to develop a therapeutic alliance. Journal of Telemedicine and Telecare 7 (suppl 1): 34-6.

Simpson S, Bell L, Knox J, et al (2005) Therapy via videoconferencing: A route to client empowerment. Clinical Psychology and Psychotherapy 12. $156-65$

Simpson S, Bell L, Britton P, et al (2006) Does video therapy work? A single case series of bulimic disorders. European Eating Disorders Review 14: 226-41.

Tang WK, Chiu H, Woo J, et al (2001) Telepsychiatry in psychogeriatric service: A pilot study. International Journal of Geriatric Psychiatry 16 : 88-93.

Wootton R, Yellowlees P, McLaren P (eds) (2003) Telepsychiatry and e-Mental Health. Royal Society of Medicine Press.

Wootton R, Craig J, Patterson V (eds) (2006) Introduction to Telemedicine (2nd edn). Royal Society of Medicine Press.

Zaylor C, Nelson EL, Cook DJ (2001) Clinical outcomes in a prison telepsychiatry clinic. Journal of Telemedicine and Telecare 7 (suppl 1): 47-9.

\section{MCOs}

Select the single best option for each question stem

\section{When using videoconferencing in psychiatric services:}

a the assessment of children is not advised

b lack of familiarity with equipment may impede successful use in clinical practice

c it is not relevant to those working in urban settings

d meetings with more than two sites are impractical

e it is not safe for undertaking suicide risk assessments.

\section{Videoconferencing technology:}

a allows up to three sites to communicate without the need for a central 'bridge'

b over internet protocol (IP) has practically limitless capacity to carry data

c through ISDN lines can be provided cheaply and quickly by most telecommunications carriers

d via Skype does not provide adequate confidentiality of patient data

e failures are rarely caused by simple errors such as disconnected cables.
3 Regarding videoconferencing costs:

a the unit costs for each session increase as videoconferencing is used more often

b there is often no need for technical support once the systems are installed

c when compared with peripheral face-to-face clinics, cost to the service provider will be reduced at a certain distance between hospital base and peripheral clinic

$d$ the structure of existing psychiatric services will not influence the utilisation and economy of a new videoconference service

e there is a large body of strong research evidence showing videoconferencing to be more cost-effective than face-to-face clinics.

\section{When using videoconferencing in} specialist services:

a psychiatry is not as well suited in routine clinical practice as several other medical specialties

b for multidisciplinary treatment of eating disorders, dietitians can treat patients by videoconference, but delivering psychological therapies in this way is not advised c patients should not move between videoconference and face-to-face treatments once treatment has started

d patients with cognitive impairment find assessment in this way too confusing to be practicable

e counselling about difficult diagnoses can be provided to patients.

\section{For videoconference sessions:}

a materials for use should be delivered to the remote location beforehand

b a mental health worker should always be with the patient

c patients have more misgivings about the technology than clinicians

d Mental Health Act assessments should be avoided for legal reasons

e the equipment allows flexibility, so there is no requirement to adhere strictly to time limits. 